\title{
The Influence of Government Policies on University Industry Collaboration in China
}

\author{
Yuan-Jian QIN and Davit MKHITARYAN* \\ Wuhan University of Technology \\ mkhitaryan_davit@yahoo.com \\ ${ }^{*}$ Corresponding author
}

Keywords: New energy vehicle, Government policy, University-industry collaboration, Technology innovation, Coupled process.

\begin{abstract}
Universities and Government agencies play important role in Firm's R\&D activities. Central and local governments are making tremendous investments in New Energy Vehicle industry in China. This paper examines the direct and indirect role of government and its policies to influence the innovation process of new electric vehicle industry. Specifically, the paper aims to examine university-industry collaboration and interaction of the government. We analyze the current model and the government policy of new energy vehicle industry and propose our new model based on our findings for government interaction to foster the new energy vehicle advancement in China. The methodology utilizes in-depth interviews with new energy vehicle manufacturers and local and regional government agencies throughout China. The results show that indirect role of government is more effective than direct influence in the industry, and specifically, in China, new energy vehicle manufacturers should follow the coupled process of innovation to achieve better results.
\end{abstract}

\section{Introduction}

Public policy in different ways can influence the extent of cooperation and the tendency of companies to collaborate with universities. One way is to provide direct funding for R\&D projects, as well as through a regulatory role, which influences the rule-sets of state universities, and the formation of intellectual property rights. Another role of public policy is to establish necessary infrastructure and intermediate organizations. In addition, government can apply soft measures to facilitate partnership, such as providing consulting services to organizations and universities. Support them to find partners for collaboration and conduct promotional activities to foster networking and increase the perception of the significance of collaboration. The New Energy Vehicle (NEV) industry is an emerging industry worldwide. The Chinese government uses the term new energy vehicles to specify plug-in electric vehicles qualified for public subsidies and includes only battery electric vehicles and plug-in hybrid electric vehicles. Enterprises and the governments globally are looking for technological innovations to decrease production costs and raise the use of new energy vehicles. Companies and the government jointly have sought various forms of collaborations to solve the problem of increasing technological progress in order to cut costs and expand the use of new energy vehicles in China. The total cost of ownership, customer response to cost, charging infrastructure, government policies, battery and electric vehicle production capacity limitations are the key variables that impact the new energy vehicle development and are currently still uncertain. Our paper will focus on the impact of government policy on new energy vehicle industry. It aims to answer two questions: how to facilitate technology innovation based on the theory of the coupled process and how government policy can improve new energy vehicle market. The research discusses the direct and indirect roles of government in university-industry collaboration process and proposes the new model of government interaction, and formulates policy suggestions for the further enhancement of sustainability of new energy vehicle industry in China. In 2015 BYD Auto became world's best selling manufacturer of highway legal light-duty plug-in electric vehicle. Batteries and their parts identified as a principal technological challenge to 
overcome in the successful development of new energy vehicle industry considering the entire production chain $[1,2]$. Despite the research and advancement done in new energy vehicle industry worldwide, still, the high manufacturing cost of batteries that drive new energy vehicles is a major obstacle - a factor accounting for nearly $50 \%$ of the total cost per unit manufactured [3]. With China's economic success and the resulting increase in its population's purchasing power, the country has become one of the world's largest consumer markets. Since 2011 passed the 500,000 unit milestone in March 2016, and the 1 million mark early in 2017, both, excluding imports. Domestically produced passenger cars account for $96 \%$ of new energy vehicle sales in China. Deliveries between 2015 and 2017 account for $93.4 \%$ of all domestically built new energy vehicle sales since 2011. Having been based on top-down process, encouraged by direct policy measures the current model of collaboration is not sufficiently market driven and resulted in innovations that lacked a context to be put to use (figure 1). Applied collaboration with firms might distract academics from engaging in long-term academic research. The results originating from such interaction with industry might not be publishable in academic journals, either due to secrecy considerations or simply because they are not sufficiently novel or systematic. In this model university-industry collaboration is not for the same purpose, the university is seeking research funds from the government by showing published results and companies are motivated by government subsidies only. There is a need to create a model where both parties will focus on market needs and product innovation. Moreover, the government in the current model is controlling both universities and businesses; this hierarchical bureaucratic structure is slowing the innovation process and making it hard to check the real outcomes, as there are over 200 new energy vehicle manufacturers in China.

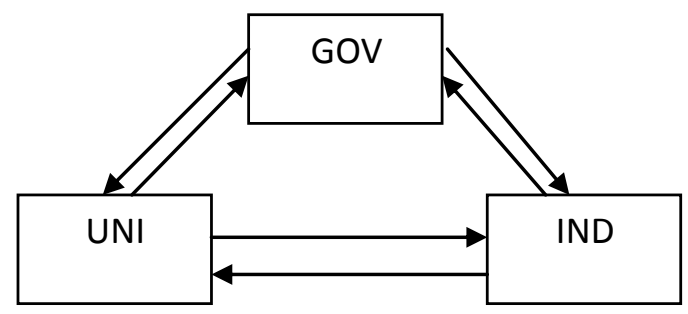

Fig. 1 Current model of interaction

\section{The Industry Problem in China}

Although standard economic theories would suggest that competition produces useful variations among models, which benefit later rounds of evaluation and absorption, there are also indications that competition has serious drawbacks. Piloting programs in many cities resulted in city leaders to overemphasize their progress to appear successful. Local governments inflated their new energy vehicle projects' successes, to increase their chances of winning further support (Pan Mingjun, 2012). Another problem has been local protectionism. Many local governments have focused on developing standards and technologies that specifically benefit their own location and local companies, rather than working toward national or international standards and goals. From the interviews with government agencies, we found that often central government and local government have misaligned incentives and goals. Fierce local competition hinders rather than encourages the development of a national formula. The absence of strict supervision from the central government loses the primary goals of city pilots and creates specialized local standards that are not widely applicable. As a result, opportunities for system-level learning are reduced.

Currently, Chinese new energy vehicle development mostly relying on local manufacturing and innovation is taking more independent way. Despite large government spendings on new energy vehicle subsidies to cut their prices and incentives to manufacturers and some advancement in technology development, there is still a technology gap between China and leading countries. There is a need to set up a separate production line for new energy vehicles, though with current sales showing slow growth manufacturers are unwilling to make large investments on $R \& D$ of new energy vehicles. Yet the government incentives for Chinese carmakers are not sufficient to focus on 
new energy vehicles, and the main problem for Chinese users is not the price but the infrastructure and insufficient incentives to encourage the use of new energy vehicles. The government national policy in China creates major trade barriers to restrict foreign technology penetrating the Chinese market. Strict intellectual property transfer terms and unavailable subsidies for imported new energy vehicles, make sales of foreign-branded new energy vehicles very hard in the domestic market. This kind of environment limits the access of Chinese consumers to foreign technologies.

\section{Methodology}

An integrated conceptual model is proposed highlighting a comprehensive set of potential factors influencing the adoption of government policy in new energy vehicle industry. The conceptual model was developed using related literature review and also by conducting interviews with government agencies, academic researchers and companies engaged in collaborative work in new energy vehicle industry in China.

\section{Literature Review}

Alliance-based innovations may radically change the customer's buying reasons and benefits from purchase. The example of growth in alliance-based competition and innovation is green technology market. To support the development of new energy vehicle industry, the Chinese government launched US\$15 billion program. In 2009 the government set the first standards and regulations when it published the development path for the advancement of the battery industry Access Regulations for New Energy Vehicle Manufacturers and Products. The infrastructure is a significant factor for the feasibility of electric cars in China [3]. Findings show that in China factors such as academic degree, annual income, number of vehicles, government policy, the opinion of friends, and tax incentives influence consumers' purchasing decisions of new energy vehicles. The study investigated the influence of government policy on the acceptance of new energy vehicles measuring four significant factors affecting buyers' choice. The findings suggest that performance properties, rather than financial privileges, are the most influential variable to determine the consumer's decision to purchase a new energy vehicle [4].

\section{Coupled Innovation Process}

Coupled innovation applies to innovation in cooperation with additional companies. These partnerships formulated as joint ventures and alliances. Through coupled innovation processes, firms obtain inter-firm relationships. Thus, their R\&D departments are collaborating to develop mutual technology [5].

\section{Tesla Motors Alliances and US Government Policy}

The U.S. government has established various incentives and regulations that urge new entrepreneurs and corporate entrepreneurs to invest in the green-technology vehicle market. An important incentive for new technologies was the Corporate Average Fuel standards, which was established in 1975. The standards had a limit of $27.5 \mathrm{mpg}$ and it was valid until 2010. In 2007, the Energy Independence and Security Act, which was enacted by the Congress, forced the automobile manufacturers to achieve a limit of $35 \mathrm{mpg}$ by 2020. Apart from the regulations, the U.S. government has established various programs in order to give financial incentives to customers. Some of those incentives are listed below: Loans for the promotion of battery research and other green-technology development for vehicles; Support for electric vehicle battery charging station implementation; The electric vehicle purchasing by the federal government. 


\section{China's Government Policy Analysis in NEV Industry}

Having interviewed government officials and company managers we identified six government policy factors which influence new energy vehicle industry in China: Guidance, Financial support, Technological support, Enforcement regulations, Foreign imports.

Guidance. The government not only provides the research funding and builds the research project, but also creates the marketing needs and enhances the social use of scientific discoveries. The role of government transformed from single financial support to the establishment of technology support policy system. Through restructuring of the technology policy system and creating more marketing need, the government can lead the business innovation and industrial transformation. The government should not be strengthened in the intervention of enterprises management but should be strengthened in leading the enterprises on the macro-respect, in order to promote the industrial upgrade and adjust the industrial structure.

Financial Support. There are two kinds of financial supporting policies: one is government purchase, and the other one is government subsidies.

Government purchase: it can reduce the risk of industrialization of new energy vehicles in the introduction stage, and trigger the consumer need and investments. Moreover, enhance the purchasing of new energy vehicle can also push the mass production of new energy vehicle and development of the related industries.

Government subsidies: it is focusing on the users of new energy vehicles. The highest subsidy is 60,000 RMB covers the individual consumers.

China's new energy vehicle policies have relied on very generous subsidies, which are not sustainable in the long run, and have emphasized local government purchase of fleet vehicles, including buses and sanitation trucks as opposed to stimulating private consumers to purchase new energy vehicles. Performance attributes, rather than financial benefits, are the most important variable to influence the consumers' decision to purchase new energy vehicle [4]. Thus, financial support from the government should be directed on building vehicle efficiency and creating conditions to encourage the use of new energy vehicles. In the current transportation system, these actions would build a friendly environment for new energy vehicles.

Technology Support. There are two variables in this policy: R\&D and Infrastructure Investments.

- $\quad$ R\&D: in order to develop the new energy vehicles, the government provides great funding to the development departments and new energy vehicle companies. In the form of National Significant and Special Vehicle Project, the government invested in the development of new energy vehicle and several main vehicle producers in China. China's government should encourage firms to collaborate with university and research institutes and provide necessary incentives for both actors.

Infrastructures: in order to achieve the industrialization, the development of new energy vehicle does not only need the mature technology for the whole car or the market guiding but also needs the supporting generated from service after the sale and the infrastructures.

Enforcement Regulations. The enforcement policy normally focuses on the fuel vehicles. The government implements the enforcement policy of the fuel vehicles on producing, sale, using and emissions at the right time and right area. The enforcement policy of fuel vehicles makes a direct promotion to the development of the electric vehicle, especially the policy about the restricted fuel vehicles emissions. Chinese government created barriers for fuel vehicle license plate registration only in cities like Beijing and Shanghai but there is no general enforcement policy throughout China. Barriers raised by the government to discourage demand for conventional vehicles will encourage consumers to choose new energy vehicles and manufacturers to develop new energy vehicles, in this way government will play an indirect role in promoting the new energy vehicle industry.

NEV Standards. In the fierce market competition, excellent marketing performance is not only depending on the technology leadership, but also on the marketing strategy, the service after the sale, and the development of the related industries. The government has to formulate an industry 
standard in a macro-strategy aspect. The industry standard consists of technology standard of new energy vehicle, auto emission standards, patent application of new energy vehicle and the alliance of new energy vehicle. The industry standard will provide a harmony environment of innovation for the companies. For example, central Beijing has in place a road space rationing scheme, a driving restriction regulation that bans conventional vehicles from entering the city for one day a week, but new energy vehicles are exempted from the restriction $[7,8]$.

Foreign Imports. All of the benefit policy of new energy vehicle in China mainly focuses on the Chinese companies. It is a challenge to the foreign new energy vehicles in pricing aspect. Chinese companies can influence the formulating of industry standard and the national standard of the new energy vehicles. This is the challenge to the foreign new energy vehicles. The technology gap between Chinese and foreign new energy vehicle makers can be closed quickly only through collaboration with international companies. Chinese manufacturers can benefit from international competition and learn about the latest technologies much more quickly than the current speed. Foreign companies in China should be able to access subsidies and the market including government procurement and the Chinese government should set similar technology standards that treat all new energy vehicle manufacturers equally. In this way will achieve strong competition, enhanced collaboration, and it will drive the adoption of the best technology. This will also implement uniform policy structure which will support continued investment in Research and Development. Based on our analysis we propose some policy recommendations (Table 1).

Table 1 Policy recommendations

\begin{tabular}{|c|c|}
\hline Technology development & Market improvement \\
\hline $\begin{array}{l}\text { - Open the domestic NEV market to } \\
\text { leading international automakers } \\
\text { - Provide equal incentives for domestic } \\
\text { and international firms } \\
\text { - Create an environment that encourages } \\
\text { NEV use, building infrastructure and } \\
\text { providing incentives to stimulate demand } \\
\text { - Focus on developing a self-sustaining } \\
\text { business model for NEV } \\
\text { - Limit the number of license register for } \\
\text { oil cars } \\
\text { - Uniform industrial standards for battery } \\
\text { and body materials }\end{array}$ & $\begin{array}{l}\text { - Public procurement and } \\
\text { corporate fleet orders } \\
\text { - Create an environment that } \\
\text { encourages NEV use, building } \\
\text { infrastructure and providing } \\
\text { incentives to stimulate demand } \\
\text { - Limit the number of license } \\
\text { register for oil cars }\end{array}$ \\
\hline
\end{tabular}

\section{Proposed Model}

The proposed model involves three main actors of collaboration and their role in it: The Government agencies, University and Industry.

Government agencies: ensuring the participation of respective parties for successful collaboration by providing incentives such as:

- Grants and special incentives for companies and universities (reduce taxes)

- Provide more scholarships for $\mathrm{PhD}$ doctorate programs in new energy vehicle industry

- Identify the strength of each university and company to collaborate to solve the specific problem (design of new energy vehicle, business model, infrastructure, market)

UNI: ensuring cooperation with industry according to its own skills and capability. Universities need to concentrate more on the determinants that greatly affect the collaboration with industry. In this way, the opportunity for strong university-industry collaboration will be reached when we know the strength of university towards successful collaboration. 
The role of the university: Estimate results, areas, and collaboration model with industry; Creation of new award system for academicians who actively engaged with industry consultation work;

Improvement of strategies to inspire more industry engagement in university; Promoting skilled alumni to a wide range of companies. Industry: with the support of government agencies ensuring the transfer of instructors' and students' knowledge to the production processes by preparing the basis for practicing scientific knowledge gained in academic settings: Set up a research lab in the university; Development new product through university; Employees training in university; Consultation work; Funding; Knowledge transfer; Product commercialization.

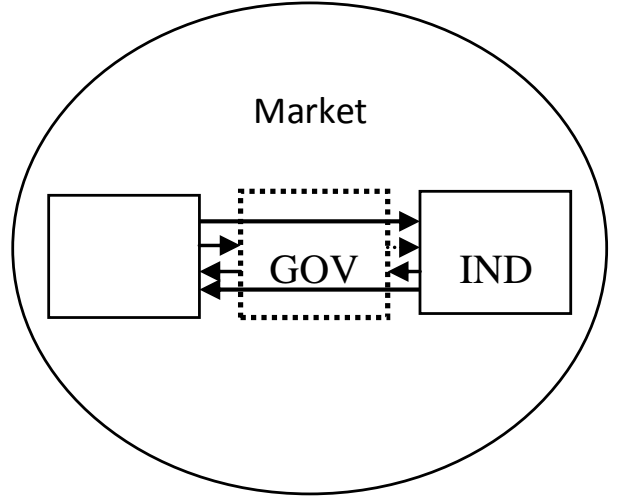

Fig. 2 Proposed model of Interaction(UNI - GOV - IND)

In our proposed model government plays an indirect role in promoting new energy vehicle development and encouraging university-industry collaboration. Government from the top down and direct role moves to the background and acts in an indirect and hidden manner, implementing policies to regulate the market and moderate university-industry collaboration. The subsidies for new energy vehicle development, instead of providing to companies directly, it can be directed to universities R\&D departments and motivate businesses to partner with those universities for mutual research. In the form of a fund, the government can finance the new energy vehicle development projects and encourage companies and other institutions to form alliances and achieve better results in technology innovation. Setting up new energy vehicle market standards and regulations and by providing same incentives and equal conditions for foreign new energy vehicles, this will create a competitive environment with advanced technology in the market and will force local developers to focus on the market and boost their capabilities and collaborations to accelerate the innovation process. The government can stimulate collaboration through soft measures, such as providing specific support services to firms and universities in the search for partners and conducting outreach activities to promote networking and raise awareness of the importance of collaboration. Government agencies should seek out technology leaders in new energy development industry to encourage them to initiate an "industry-led" focus program. As industry takes on the project as its own and draws academics as well, or vice versa, who can say where top-down ends and the bottomup process begins. It may be more accurate to recognize both processes going on simultaneously and in tandem. Such dual track for innovation promotion may be more productive than any single path. An innovation network within an organization is dedicated to create a structure that fosters innovation but needs not control the innovation outcomes. The positive detail of creating a comprehensive innovation ecosystem is that actors engaged in innovative projects will reach out to each other directly to solve problems rather than requiring a central office to mediate all communications. This loosely-coupled structure helps to create a culture of innovation, rather than top-down governance, allowing innovative ideas to not only be formed - but also thrive and grow.

\section{Conclusions}

The government plays significant, critical factor for new energy vehicle industry. In China, the government influence directly to promote new energy vehicle development. The right policies can 
facilitate the innovation process and also create demand for new energy vehicles. Based on the data collected and on the analysis that was carried out the conclusions can be drawn. Government's financial support policy should be based on vehicle efficiency and create an environment that encourages new energy vehicle use. The necessary infrastructure and incentives make a bigger influence on demand than subsidies. Barriers raised by the government to discourage demand for fuel vehicles will encourage new energy vehicle development. A mutual partnership is a significant driver for China as it seeks new technology, develops markets and ensures the development of a vehicle market that both meets and sets global standards. Our model with three main actors (university, industry, and government) established successful collaboration between university and industry. Government plays an indirect and hidden role in collaboration process, where government's indirect policies influence technology development and create market demand for new energy vehicles. Apply open innovation and coupled process by establishing R\&D collaborations with major companies and universities worldwide to further develop their innovative technologies. Mass electric vehicle deployment in China requires substantial policy adjustment. In particular, it will be necessary to permit foreign new energy vehicle technology free market entry. In turn, this requires greater foreign IP protection. China must also consolidate its domestic industry and place greater emphasis on smaller, cheaper vehicles aimed at domestic, lower-end markets.

\section{References}

[1] Castro, B. H. R. D., Barros, D. C., \& Veiga, S. G. D. (2013). Baterias automotivas: panorama da industria no Brasil, as novas tecnologias e como os veiculos elétricos podem transformar o mercado global. BNDES Setorial, 37, 443-496.

[2] Fournier, G., Hinderer, H., Schmid, D., Seign, R., \& Baumann, M. (2012). The new mobility paradigm: Transformation of value chain and business models. Enterprise and work innovation studies, 8, 9-40.

[3] Kimble, C., \& Wang, H. (2012). Transistors, electric vehicles and leapfrogging in China and Japan. Journal of Business Strategy, 33(3), 22-29.

Liu, Y., \& Kokko, A. (2013). Who does that in China's new energy vehicle industry? Energy Policy, 57, 21-29.

[4] Zhang, X., Wang, K. Hao, Y., Fan, J.L. \& Wei, Y. M. (2013). The impact of government policy on preference for NEVs: The evidence from China. Energy Policy, 61, 382-393.

[5] Mazzola, E., Bruccoleri, M., \& Perrone, G. (2012). The effect of inbound, outbound and coupled innovation on performance. International Journal of Innovation Management, 16(6), 8-9.

[6] Holmberg, S. (2011). Emerging Green-Technology Entrepreneurs: Entrepreneurial Pathways to Growth in the Hybrid and Plug-In Hybrid/Electric Vehicle Space. ICSB World Conference Paper, 3-8. Stockholm.

[7] Gong, H., Wang, M. Q., \& Wang, H (2013). New energy vehicles in China: Policies, demonstration, and progress. Mitigation and Adaptation Strategies for Global Change Journal, $18(2), 207-228$. 